\title{
Global static stability and its relation to gravity waves in the middle atmosphere
}

\author{
Xiao Liu ${ }^{1,2}$, JiYao $\mathrm{Xu}^{2,3}{ }^{*}$, and Jia Yue ${ }^{4,5}$ \\ ${ }^{1}$ Henan Engineering Laboratory for Big Data Statistical Analysis and Optimal Control, School of Mathematics and Information Sciences, Henan Normal \\ University, Xinxiang Henan 453007, China; \\ ${ }^{2}$ State Key Laboratory of Space Weather, Center for Space Science and Applied Research, Chinese Academy of Sciences, Beijing 100190, China; \\ ${ }^{3}$ School of Astronomyand Space Science, University of the Chinese Academy of Science, Beijing 100049, China; \\ ${ }^{4}$ Catholic University of America, Washington, DC 20064, USA; \\ ${ }^{5}$ National Aeronautics and Space Administration (NASA) Goddard Space Flight Center, Greenbelt, MD 20771, USA
}

Key Points:

- Global atmospheric static stability (defined by $N^{2}$ ) exhibits annual and semiannual oscillations that are latitude and height dependent

- The peaks of $N^{2}$ shift from winter $(\leq 70 \mathrm{~km})$ to summer $(\geq 80 \mathrm{~km})$ and are caused by inversion layers at low latitudes and a cold summer mesopause at high latitudes

- At high latitudes, $N^{2}$ correlates well with the amplitude of gravity waves and is responsible for the peaks of gravity waves shifting from winter $(\leq 70 \mathrm{~km})$ to summer $(\geq 80 \mathrm{~km})$

Citation: Liu, X., Xu, J. Y., and Yue, J. (2020). Global static stability and its relation to gravity waves in the middle atmosphere. Earth Planet. Phys., 4(5), 504-512. http://doi.org/10.26464/epp2020047

\begin{abstract}
The global atmospheric static stability $\left(N^{2}\right)$ in the middle atmosphere and its relation to gravity waves (GWs) were investigated by using the temperature profiles measured by the Sounding of the Atmosphere using Broadband Emission Radiometry (SABER) instrument from 2002 to 2018 . At low latitudes, a layer with enhanced $N^{2}$ occurs at an altitude of $20 \mathrm{~km}$ and exhibits annual oscillations caused by tropopause inversion layers. Above an altitude of $\sim 70 \mathrm{~km}$, enhanced $N^{2}$ exhibits semiannual oscillations at low latitudes caused by the mesosphere inversion layers and annual oscillations at high latitudes resulting from the downward shift of the summer mesopause. The correlation coefficients between $N^{2}$ and GW amplitudes can be larger than 0.8 at latitudes poleward of $\sim 40^{\circ} \mathrm{N} / \mathrm{S}$. This observation provides factual evidence that a large $N^{2}$ supports large-amplitude GWs and indicates that $N^{2}$ plays a dominant role in maintaining GWs at least at high latitudes of the middle atmosphere. This evidence also partially explains the previous results regarding the phase changes of annual oscillations of GWs at high latitudes.
\end{abstract}

Keywords: atmospheric static stability; gravity waves; annual oscillation; semiannual oscillation; mesopause

\section{Introduction}

In a stably stratified atmosphere, an air parcel oscillates adiabatically around its equilibrium because of the buoyancy force and gravitational force. The oscillation frequency is referred to as the buoyancy frequency (or Brunt-Väisälä frequency) and is denoted as $N$. The square of the buoyancy frequency $\left(N^{2}\right)$ is a measure of the atmospheric static stability. The static stability is determined by the structure of the background atmosphere and has an important influence on the generation, propagation, and dissipation of atmospheric waves. In turn, the momentum and energy transported by atmospheric waves control the atmospheric structures in the mesosphere (Andrews et al., 1987; Holton, 2004). Thus, static stability acts as a bridge between the background at-

Correspondence to: J. Y. Xu, xujy@nssc.ac.cn

Received 11 MAY 2020; Accepted 28 MAY 2020.

Accepted article online 28 JUN 2020.

C 2020 by Earth and Planetary Physics. mosphere and atmospheric waves.

In the troposphere and stratosphere, static stability is mainly controlled by the temperature lapse rate and the height of the tropopause. Generally, below (above) the tropopause, the temperature decreases (increases) with increasing height and results in lower (higher) values of static stability. This general scenario does not hold above the tropopause region because of the presence of tropopause inversion layers (TIL). The TIL is defined as a region with enhanced static stability just above the cold-point tropopause (Birner et al., 2002, 2006). Recent studies have shown that the TIL and the associated static stability enhancement occur at all latitudes, as revealed by satellite and ground-based observations, as well as reanalysis data and model simulations (Grise et al., 2010; Gettelman et al., 2011; Zhang YH et al., 2015, 2019; Liu HL, 2017). The enhanced static stability above the tropopause is closely related to the wind shear and gravity waves (GWs) in this region (Liu HL, 2007, 2017; Sunilkumar et al., 2015, 2017; Zhang YH et al., 2015, 2019; Pilch Kedzierski et al., 2016). Through model simula- 
tions, Liu HL (2017) showed that large wind shears exist in the TIL region. This is because enhanced static stability in the TIL allows wind shears to attain large values before the onset of instability (Liu HL, 2007). The wind shears can be attributed to the background atmosphere and atmospheric waves. Through a spatialscale decomposition, Liu HL (2017) showed that large wind shears are mainly caused by GWs and modulated by tidal waves (Yue J et al., 2010; Liu $X$ et al., 2014). By analyzing high-resolution radiosonde measurements, Zhang $\mathrm{YH}$ et al. $(2015,2019)$ showed that upward-propagating GWs have maxima in the TIL, which is at $\sim 1$ $\mathrm{km}$ above the tropopause. These results indicated that the enhanced static stability in the TIL provides favorable conditions for GW propagation and thus for the large wind shears (Sunilkumar et al., 2015, 2017; Liu HL, 2017).

In the mesosphere and lower thermosphere region, static stability has a similar configuration as that around the tropopause. Above the mesopause, the temperature increases with height. This results in enhanced static stability, which can sustain large winds and wind shears. Gravity waves are the main contributors to the large winds and wind shears (Liu HL, 2007, 2017; Liu X et al., 2014), forming a positive feedback process among the static stability, GWs, large winds, and wind shears. In the mesosphere, there is a layer with a thickness of $\sim 10 \mathrm{~km}$ at $\sim 65 \mathrm{~km}$ and $85 \mathrm{~km}$, in which the temperature enhancement can be up to $\sim 20$ to $50 \mathrm{~K}$, called the mesosphere inversion layer (MIL; Leblanc and Hauchecorne, 1997; Meriwether and Gerrard, 2004; Xu JY et al., 2007b; Fechine et al., 2008; Gan Q et al., 2012). In the MIL, the temperature increases with height and results in enhanced static stability. For example, Gan Q et al. (2012) showed, by using temperature data derived from the Sounding of the Atmosphere using Broadband Emission Radiometry (SABER) instrument (Russell III et al., 1999) onboard the Thermosphere lonosphere Mesosphere Energetics and Dynamics (TIMED) satellite, that the monthly mean amplitude of the lower MILs exhibits semiannual oscillations (SAOs) with peaks in spring and autumn at an altitude range of $\sim 76$ to $83 \mathrm{~km}$ at low latitudes. At the middle latitudes, the monthly mean amplitude of the lower MILs exhibits annual oscillations (AOs) with peaks in winter and at an altitude range of $\sim 70$ to $79 \mathrm{~km}$. The increasing (decreasing) temperature above (below) the bottom of the MIL produces a sharp increment (decrement) of static stability in the mesosphere. As a consequence, the seasonal and latitudinal variations of the MIL, such as its amplitude and height, will induce corresponding variations in the static stability. It can be speculated that the positive feedback between the static stability and GWs would be similar in the MIL.

Using temperature profiles measured by the SABER instrument, Liu $X$ et al. (2017) showed that the $A O$ of the monthly zonal mean GW potential energy undergoes a clear phase shift at latitudes poleward of $40^{\circ} \mathrm{N} / \mathrm{S}$ (Fig. 3 of their paper). The peaks of the GW potential energy shift from winters below an altitude (hereafter, referred to as $z$ ) of $\sim 70 \mathrm{~km}$ to summers above $z \sim 80 \mathrm{~km}$, whereas at $z$ $\sim 70-80 \mathrm{~km}$, the SAO is dominant. The global GW potential energy (Fig. $2 \mathrm{~b}$ of their paper) exhibits a much weaker peak at $z \sim 75 \mathrm{~km}$, which corresponds to the altitudes of the phase shifts of the $A O$ and SAO. We suggest that when the altitudes of the MIL (Gan Q et al., 2012) are compared with phase shifts of the AO and SAO in the zonal mean temperature (Shepherd et al., 2004; Xu JY et al., 2007b), $N^{2}$ might link the phase shifts of the interannual oscillations of GWs with the MILs, as well as the interannual oscillations of the zonal mean temperature. The purpose of this study is to illustrate the global climatology of the static stability and its relation to GWs.

Understanding the global static stability and its seasonal, latitudinal, and altitude variations may have important implications for global GW variations. In this study, we examined the SABER temperature profiles to characterize the global distribution and intraannual oscillations of the static stability. In addition, we examined the relations between the static stability and GWs, which were also derived from the SABER temperature profiles.

\section{Data and Method}

The temperature profiles (V2.0) measured by the SABER instrument (Russell et al., 1999) over a 17-year period (2002-2018) were used in this study. These profiles cover an altitude range of $\sim 15-110 \mathrm{~km}$ and a latitude range of $53^{\circ} \mathrm{S}-83^{\circ} \mathrm{N}$ or $83^{\circ} \mathrm{S}-53^{\circ} \mathrm{N}$. The temperature accuracy is $1-3 \mathrm{~K}$ from 30 to $80 \mathrm{~km}$ and $5-10 \mathrm{~K}$ from 90 to $100 \mathrm{~km}$, as reported on the SABER website (http://saber. gats-inc.com/; Remsberg et al., 2008).

The GW extraction method was similar to that by Liu X et al. (2017, 2019, and references therein). First, the daily SABER temperature profiles, $T(z)$, in a latitude band of $5^{\circ}$ were selected. Second, at each altitude, the selected data were fitted by harmonics with zonal wavenumbers ranging from 0 to 6 to obtain the background temperature, $T_{b}(z)$, and residual temperature, $T_{r}(z)=T(z)-T_{b}(z)$. The component of wavenumber 0 was the zonal mean temperature, $\bar{T}(z)$. Third, a band-pass filter with a cutoff wavelength of $5-25 \mathrm{~km}$ was applied on the residual profiles to obtain the GW perturbation profiles, $T^{\prime}(z)$. The above-mentioned three steps were applied on the ascending and descending nodes, respectively, such that they minimized the influence of tides on GWs (Preusse et al., 2009; Yamashita et al., 2013). Finally, the static stability was calculated according to the method of Holton (2004),

$$
N^{2}(z)=\left[\frac{g}{\bar{T}(z)}\left(\frac{\mathrm{d} \bar{T}(z)}{\mathrm{d} z}+\frac{g}{c_{p}}\right)\right]
$$

where $g$ is the gravitational acceleration and $c_{p}=1004.5 \mathrm{~J}$. $\mathrm{kg}^{-1} \cdot \mathrm{K}^{-1}$ is the specific heat for dry air at a constant pressure. If $N^{2}>0$, the atmosphere is statically stable and the air parcel will oscillate around its equilibrium level for a period of $2 \pi / N$. Thus, $N$ is also referred to as the buoyancy frequency or Brunt-Väisälä frequency. If $N^{2}=0$, the atmosphere is statically neutral and the air parcel will remain at a neutral equilibrium level. If $N^{2}<0$, the atmosphere is statically unstable and the air parcel will be displaced far from its equilibrium level. The strength of a GW is measured by its amplitude, $\left|T^{\prime}\right|$. We did not use the GW potential energy $\left(E_{p}(z)=\frac{1}{2}[g / N]^{2}\left[\left|T^{\prime}\right| / \bar{T}\right]^{2}\right)$ to measure GWs because it contains $N^{2}$, which affects the correlations between static stability and GWs. In each latitude band, we obtained one $N^{2}$ profile and one daily zonal mean profile, $\left|T^{\prime}\right| / \bar{T}$. The latitude bands had centers from $50^{\circ} \mathrm{S}$ to $50^{\circ} \mathrm{N}$, with a step of $2.5^{\circ}$ and an overlap of $2.5^{\circ}$. 


\section{Climatology of the Global Static Stability}

\subsection{General Features of the Global Static Stability}

Figure 1 shows time-height sections of the monthly zonal mean $\mathrm{N}^{2}$ and temperature at four latitude bands of the northern hemisphere (left) and southern hemisphere (right). Figure 1 provides a general picture of the altitude, latitude, and seasonal variations of $N^{2}$ and temperature. The $N^{2}$ is smaller in the lower mesosphere $(z$ $\sim 50-70 \mathrm{~km}$ ) than at the other altitudes. The largest $N^{2}$ occurs above the mesopause (blue dots) because of the sharp increase in the lower thermospheric temperature. At $5^{\circ} \mathrm{N} / \mathrm{S}$, the quasi-biennial oscillations of $N^{2}$ can be seen below $z \sim 45 \mathrm{~km}$ because of the quasi-biennial oscillations in the lower stratosphere (Baldwin et al., 2001). The enhanced $N^{2}$ can be seen in the bottom of the stratosphere $(z \sim 20 \mathrm{~km})$ as compared with that above $z \sim 25 \mathrm{~km}$ in the stratosphere. Moreover, the enhanced $N^{2}$ can be seen in the middle mesosphere $(z \sim 80 \mathrm{~km})$ as compared with that at other heights of the mesosphere.

The altitude variations of $N^{2}$ also depend on the latitude and season. At $5^{\circ} \mathrm{N} / \mathrm{S}$ and $20^{\circ} \mathrm{N} / \mathrm{S}$, a layer with enhanced $N^{2}$ occurs at $z \sim 20$ $\mathrm{km}$. This layer is just above the cold-point tropopause and is associated with the TIL (Birner et al., 2002, 2006; Gettelman et al., 2011). Below the TIL, $N^{2}$ decreases sharply with decreasing height. At $35^{\circ} \mathrm{N} / \mathrm{S}$, an enhanced $N^{2}$ associated with the TIL can still be seen, but it is much weaker than that at lower latitudes. The TIL revealed here coincides with previous results based on observations from satellite (Grise et al., 2010), radiosonde (Zhang YH et al., 2015, 2019), and reanalysis data (Pilch Kedzierski et al., 2016), as well as model simulations (Liu $\mathrm{HL}, 2007$ ). At $50^{\circ} \mathrm{N} / \mathrm{S}$, the enhanced $N^{2}$ associated with the TIL cannot be seen. This is because the height of the tropopause decreases from $z \sim 17 \mathrm{~km}$ at lower latit-

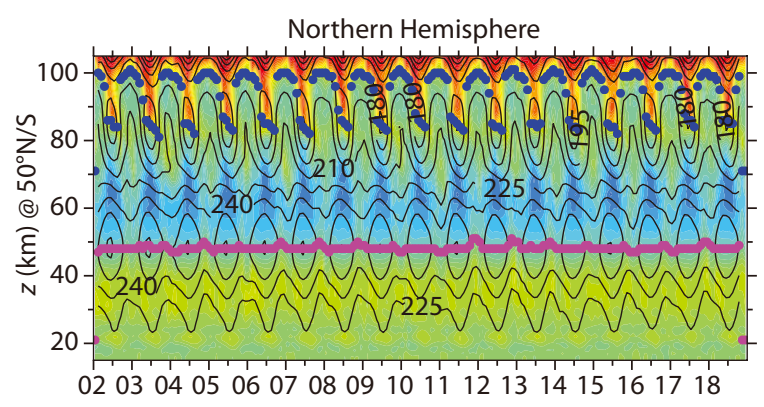

\section{Southern Hemisphere}

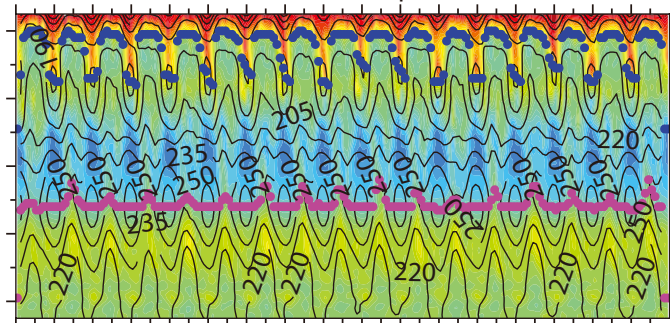

0203040506070809101112131415161718

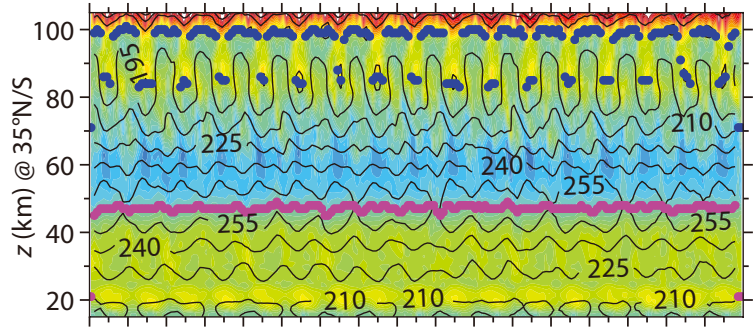

0203040506070809101112131415161718
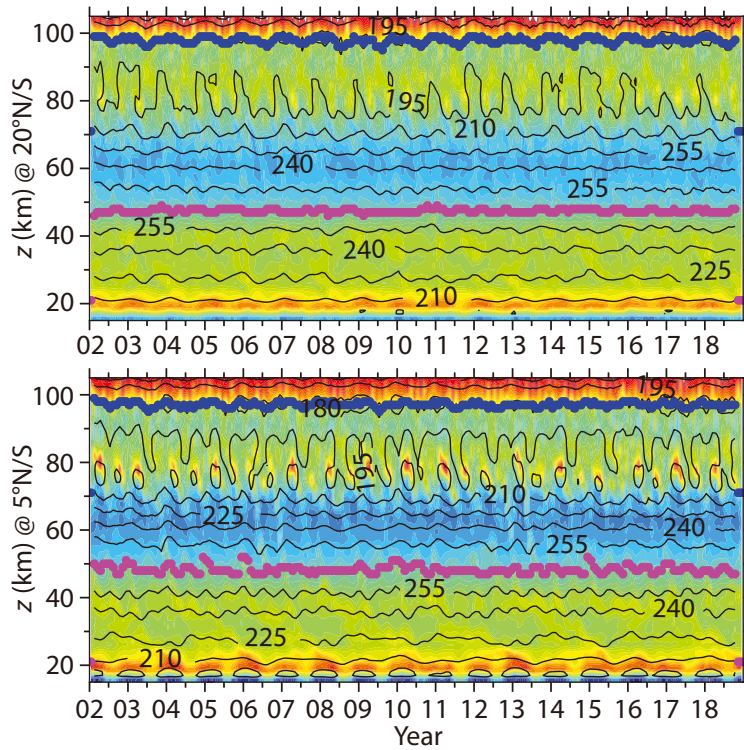

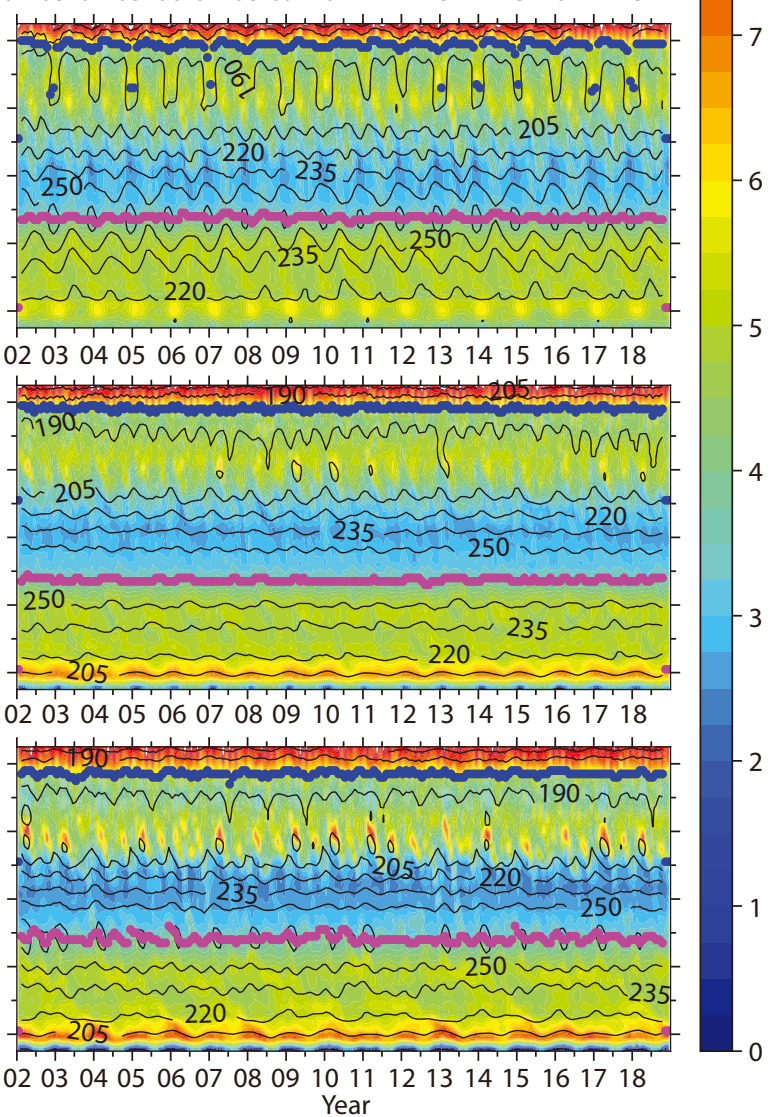

Figure 1. Time-height sections of the monthly zonal mean static stability ( $N^{2}$, colors) and temperature (lines with contour intervals of $\left.15 \mathrm{~K}\right)$ at four latitude bands of the northern and southern (right) hemispheres. The blue and magenta dots show the cold-point mesopause and stratopause, respectively. The ticks on the $x$-axis mark the beginning of each year. 
udes to $z \sim 10 \mathrm{~km}$ at high latitudes (Grise et al., 2010). The altitude coverage of the SABER measurements can be as low as $z \sim 15 \mathrm{~km}$, although uncertainties in the measurements are relatively greater below $z \sim 20 \mathrm{~km}$ than above $z \sim 20 \mathrm{~km}$. Through comparisons between Figure 1 and the previous results, we found that the enhanced $N^{2}$ associated with the TIL could be reasonably revealed by the SABER measurements at latitudes equatorward of $35^{\circ} \mathrm{N} / \mathrm{S}$. The enhanced $N^{2}$ associated with the TIL exhibits $A O$ with peaks during January and February in the lower latitudes (i.e., $5^{\circ} \mathrm{N} / \mathrm{S}$ and $\left.20^{\circ} \mathrm{N} / \mathrm{S}\right)$. At $35^{\circ} \mathrm{N}\left(35^{\circ} \mathrm{S}\right)$, the enhanced $N^{2}$ associated with the TIL is much weaker than that in the lower latitudes, and it exhibits $A O$ with peaks during June and July (January and February). The amplitudes and phases of the AO and SAO in $N^{2}$ associated with the TIL were quantified through harmonic fitting, as presented in the next subsection.

Another layer with enhanced $N^{2}$ occurs in the upper mesosphere (>70 km). This layer is associated with the MIL (e.g., Meriwether and Gerrard, 2004). The layer of enhanced $N^{2}$ associated with the MIL extends from the tropical region to high latitudes, but its seasonal variations depend on the latitudes. At $5^{\circ} \mathrm{N} / \mathrm{S}$ and $20^{\circ} \mathrm{N} / \mathrm{S}$, the enhanced $N^{2}$ at $z \sim 75-85 \mathrm{~km}$ exhibits SAO with peaks in spring and autumn. This oscillation corresponds to the tropical MIL, in which the temperature increases with height. Moreover, the amplitude of the $S A O$ at $5^{\circ} \mathrm{N} / \mathrm{S}$ is larger than that at $20^{\circ} \mathrm{N} / \mathrm{S}$. This is because the MIL has peaks in spring and autumn in the tropical region (Xu JY et al., 2007b) and the tropical MIL is mainly induced by diurnal migrating tides (Xu JY et al., 2009; Gan Q et al., 2012). At $35^{\circ} \mathrm{N} / \mathrm{S}$ and $50^{\circ} \mathrm{N} / \mathrm{S}$, the enhanced $N^{2}$ above $z \sim 85 \mathrm{~km}$ might be associated with both the MIL during winter (Gan Q et al., 2012) and the downward shift of the mesopause during summer ( $\mathrm{Xu}$ JY et al., 2007a). The enhancement of $N^{2}$ above $z \sim 85 \mathrm{~km}$ is more prominent at $50^{\circ} \mathrm{N} / \mathrm{S}$ than at $35^{\circ} \mathrm{N} / \mathrm{S}$ in summer. This is because the temperature increases sharply with height in the lower thermosphere, which begins at a lower height $(\sim 85 \mathrm{~km})$ because of the downward shift of the mesopause (blue dots) in summer (Xu JY et al., 2007a).

\subsection{AO and SAO of the Global Static Stability}

To quantify the $A O$ and $S A O$ of $N^{2}$, we applied harmonic fitting to the time series of the monthly zonal mean $N^{2}$ at each height and latitude. The fitting function is expressed as

$$
\begin{aligned}
N^{2}(t)= & A_{0}+A_{\mathrm{SAO}} \cos \left[\frac{2 \pi}{6(\text { month })}\left(t-\theta_{\mathrm{SAO}}\right)\right] \\
& +A_{\mathrm{AO}} \cos \left[\frac{2 \pi}{12(\text { month })}\left(t-\theta_{\mathrm{AO}}\right)\right],
\end{aligned}
$$

where $A_{0}$ is the mean $N^{2}$ over the 17 years, and $A_{\mathrm{AO}}$ and $A_{\mathrm{SAO}}\left(\theta_{\mathrm{AO}}\right.$ and $\left.\theta_{S A O}\right)$ are the amplitudes (phases) of $A O$ and $S A O$, respectively. The phases correspond to the peaks of oscillations. Figure 2 shows the latitude-height sections of the amplitudes and phases of the AO and SAO.

From Figure 2, we can see that at latitudes poleward of $\sim 35^{\circ} \mathrm{S}$, the $\mathrm{AO}$ is prominent at $z \sim 55-70 \mathrm{~km}$ with the peak in summer (June-July-August) and at $z \sim 85-105 \mathrm{~km}$ with the peak in winter (December-January-February) in the southern hemisphere. In contrast, at latitudes poleward of $\sim 30^{\circ} \mathrm{N}$, the $\mathrm{AO}$ is prominent at $z$ $\sim 60-75 \mathrm{~km}$ with the peak in winter and at $z \sim 82-105 \mathrm{~km}$ with the peak in summer in the northern hemisphere. Between these two regions with prominent $A O$, the $A O$ is much weaker in both hemispheres at high latitudes. The phase shift crossing this thin layer is mainly induced by the downward shift of the cold summer mesopause (shown as blue dots in Figure 1). During the summer months of each hemisphere and above the cold summer mesopause ( 82-85 km), the temperature increases with height and results in a larger value of $N^{2}$ (Xu JY et al., 2007a). Moreover, the downward shift of the cold summer mesopause makes the vertical temperature gradient more negative because the height of the stratopause (shown as magenta dots in Figure 1) does not change as much as that of the mesopause. The hemispheric asymmetry of the AO amplitude, which is larger in the northern hemisphere than in the southern hemisphere at high latitudes, results from the hemispheric asymmetry of the mesopause ( $\mathrm{Xu} J \mathrm{~J}$ et al., 2007a).

At low latitudes, the $A O$ is prominent around the tropopause region, which is separated by a thin layer of weak $A O$ at $z \sim 18 \mathrm{~km}$. The peak of the AO shifts from August below $z \sim 18 \mathrm{~km}$ to March above $z \sim 18 \mathrm{~km}$. This phase shift is induced by the AO of the TIL and the height of the stratopause, as reported by Grise et al. (2010). Those authors analyzed more than 6 years of global positioning system radio occultation temperature profiles and showed that the tropical TIL and tropopause are at a greater height from December to May than from July to September (Fig. 5 of Grise et al., 2010). A similar situation occurs at $z \sim 70-80 \mathrm{~km}$, and a thin layer of weak AO occurs at $z \sim 75 \mathrm{~km}$. The peak of AO shifts from below $z \sim 75 \mathrm{~km}$ in September to above $z \sim 75 \mathrm{~km}$ in April. This phase shift might be induced by the MIL and the enhanced diurnal tides around the spring equinox above $z \sim 75 \mathrm{~km}$ (Xu JY et al., 2007b; Gan Q et al., 2012).

A prominent SAO occurs at $z \sim 75-82 \mathrm{~km}$ in the tropical region and extends to the middle latitudes $\left(\sim 35^{\circ} \mathrm{N} / \mathrm{S}\right)$ with the phase in April/October. The SAO has another peak at $z \sim 70-75 \mathrm{~km}$ with the phase in June/December. These two peaks in the tropical regions appear to be separated by a thin layer at $z \sim 75 \mathrm{~km}$. This is a consequence of the SAO in the background temperature and because the bottom of the MIL is at $z \sim 75 \mathrm{~km}$ in the tropical region in spring and autumn (Shepherd et al., 2004; Xu JY et al., 2007b; Gan $Q$ et al., 2012). The SAO has peaks at the latitudes poleward of $45^{\circ} \mathrm{N} / \mathrm{S}$ and in the height ranges of $90-100 \mathrm{~km}$ in January/June.

The latitudinal dependencies and the phase shifts of the $A O$ and SAO of $N^{2}$ are summarized below. The AO is prominent at high latitudes. Specifically, at southern high latitudes, the phase of the $A O$ shifts from summer at $z \sim 55-70 \mathrm{~km}$ to winter at $z \sim 85-105 \mathrm{~km}$. At northern high latitudes, the phase of the AO shifts from winter at $z$ $\sim 60-75 \mathrm{~km}$ to summer at $z \sim 82-105 \mathrm{~km}$. The SAO is prominent at $z \sim 70-82 \mathrm{~km}$ in the tropical region. The phase shifts from $z$ $\sim 70-75 \mathrm{~km}$ in June/December to $z \sim 75-82 \mathrm{~km}$ in April/October.

\section{Correlations Between $\boldsymbol{N}^{\mathbf{2}}$ and GWs}

For freely propagating GWs in a stable wind environment, a larger (smaller) $N^{2}$ sustains GWs reaching a larger (smaller) amplitude before breaking because of dynamic or static instability. Because 

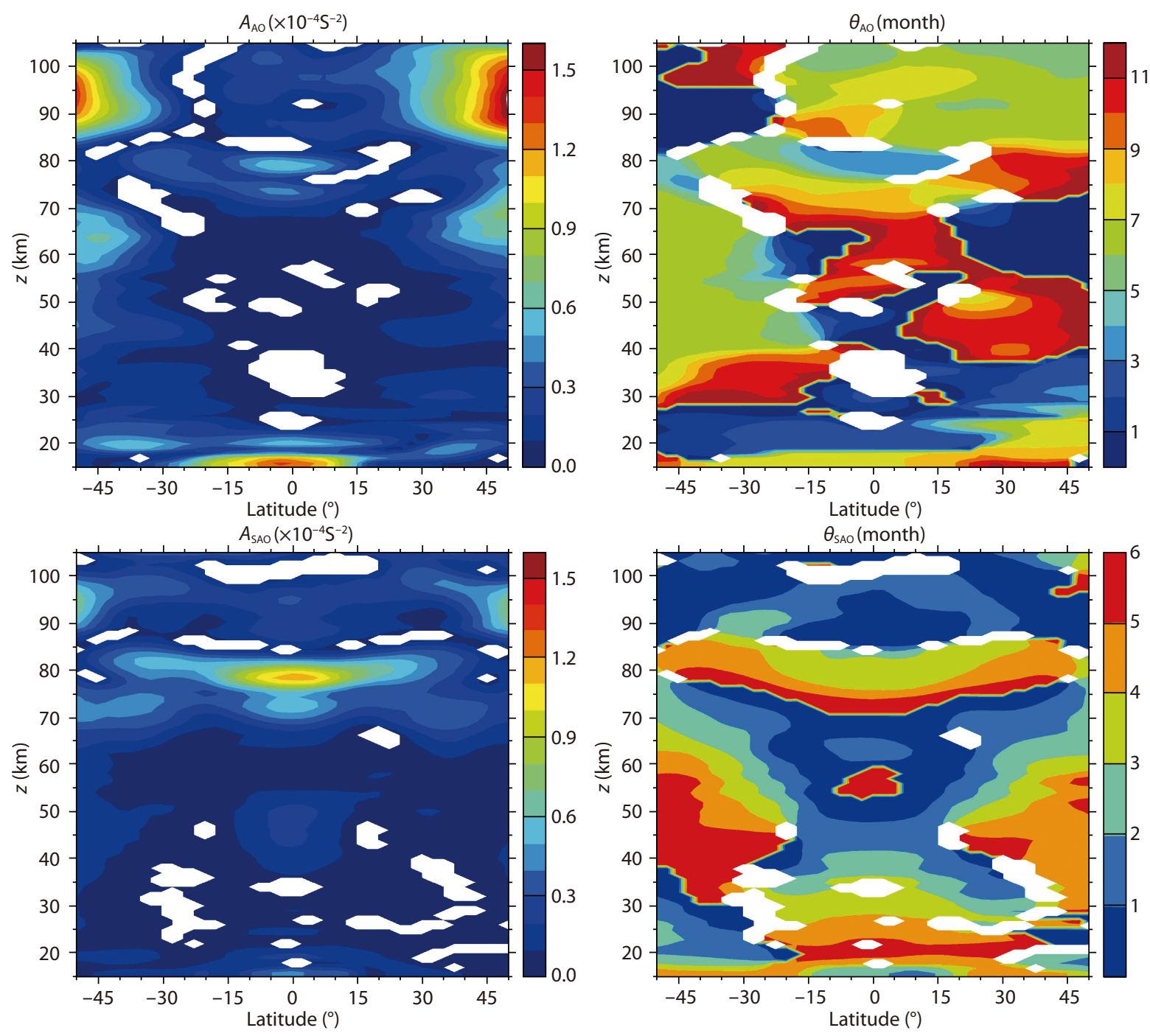

Figure 2. Latitude-height sections of the amplitudes (left) and phases (right) of the AO (top) and SAO (bottom) of the monthly zonal mean static stability $\left(N^{2}\right)$. The white regions indicate amplitudes below the threshold of the $95 \%$ confidence level according to Student's $t$-test. Same scales are used in $x$-axis and $y$-axis, respectively in each panel.

GWs are the dominant contribution to wind shear (Liu HL, 2007, 2017), the local Richardson number (Ri) is defined by Fritts and Rastogi (1985) as

$$
R i=\frac{N^{2}}{\left(\partial u^{\prime} / \partial z\right)^{2}+\left(\partial v^{\prime} / \partial z\right)^{2}}
$$

where $u^{\prime}$ and $v^{\prime}$ are zonal and meridional horizontal velocity perturbations attributable to GWs. The $R i$ is measured as the ratio between $N^{2}$ and GW-induced wind shear. In this work, only the GW-induced temperature is derived from SABER observations. A relation should exist between GW-induced wind shear and temperature based on the polarization for medium- and low-frequency GWs. The relations among $u^{\prime}, v^{\prime}$ and $\left|T^{\prime}\right| / T_{0}$ are (Fritts and Rastogi, 1985; Eckermann et al., 1995; Gubenko et al., 2008)

$$
v^{\prime}=-\mathrm{i}(f / \omega) u^{\prime}, \mathrm{i}=\sqrt{-1} \text { and }\left|u^{\prime}\right| \approx \frac{g}{N \sqrt{1-f^{2} / \omega^{2}}} \frac{\left|T^{\prime}\right|}{T_{0}},
$$

where $f$ and $\omega$ are inertial and intrinsic frequencies of GW, respect- ively. Substituting Equation (4) into (3), we have

$$
R i=\frac{N^{2}}{k_{z}^{2}\left(1-f^{2} / \omega^{2}\right)\left|u^{\prime}\right|^{2}}=\frac{N^{4}}{g^{2} k_{z}^{2}\left(\left|T^{\prime}\right| / T_{0}\right)^{2}},
$$

where $k_{z}$ is the vertical wavenumber of the GW. According to the threshold for dynamic instability $(R i=1 / 4)$, we have

$$
N^{2}=\frac{1}{4} k_{z}^{2}\left(1-f^{2} / \omega^{2}\right)\left|u^{\prime}\right|^{2}=\frac{g}{2} k_{z}\left|T^{\prime}\right| / T_{0} .
$$

Equation (6) shows that $N^{2}$ is proportional to the product of $k_{z}$ and $\left|T^{\prime}\right| / T_{0}$. Here, we concentrate on the correlations between $N^{2}$ and $\left|T^{\prime}\right| / T_{0}$, and the correlations between $N^{2}$ and $k_{z}$ will be examined in a future work.

The results in the previous section illustrate that the amplitudes and phases of the $A O$ and SAO of $N^{2}$ depend on latitude and height. This might influence the corresponding variations of GWs. Previous studies have shown that the amplitudes and phases of AO (SAO) of GWs are also dependent on latitude and height (Krebsbach and Preusse, 2007; John and Kumar, 2012; Zhang Y et 
al., 2012; Liu $X$ et al., 2017). To explore the possible relations between $N^{2}$ and GWs, Figure 3 shows the time series of the normalized trimonthly running mean $N^{2}$ (black) and $\left|T^{\prime}\right| / T_{0}$ (red) at two heights in three representative latitudes (Figure $3 a-3 c$ ) and the latitude-height distributions of the correlation coefficients (CC, Figure 3d) between $N^{2}$ and $\left|T^{\prime}\right| / T_{0}$. The representative time series of $N^{2}$ at $50^{\circ} \mathrm{N} / \mathrm{S}$ have prominent $A O$ with an antiphase between $z=90 \mathrm{~km}$ and $z=65 \mathrm{~km}$. The representative time series of $N^{2}$ at the equator have prominent SAO with an antiphase between $z=80 \mathrm{~km}$ and $z=65 \mathrm{~km}$ (Figure 2).

From Figures $3 a 1$ and $3 a 2$, we can see that the temporal variation of $\left|T^{\prime}\right| / T_{0}$ at $50^{\circ} \mathrm{N}$ is almost in phase with that of $N^{2}$ and that their
$C C$ are 0.96 and 0.87 at $90 \mathrm{~km}$ and $65 \mathrm{~km}$, respectively. The temporal variation of $N^{2}$ and $\left|T^{\prime}\right| / T_{0}$ at $90 \mathrm{~km}$ is almost antiphase with that at $65 \mathrm{~km}$. At $50^{\circ} \mathrm{S}$ (Figures $3 \mathrm{~b} 1$ and $3 \mathrm{~b} 2$ ), the $C C$ between $N^{2}$ and $\left|T^{\prime}\right| / T_{0}$ are 0.89 and 0.81 at $90 \mathrm{~km}$ and $65 \mathrm{~km}$, respectively. The CC at $50^{\circ} \mathrm{S}$ are slightly lower than those at $50^{\circ} \mathrm{N}$ because of the presence of the SAO in $\left|T^{\prime}\right| / T_{0}$ at $90 \mathrm{~km}$ and in $N^{2}$ at $65 \mathrm{~km}$. At $50^{\circ} \mathrm{N} / \mathrm{S}$, the phases of $N^{2}$ and $\left|T^{\prime}\right| / T_{0}$ are nearly identical and shift from winter at $65 \mathrm{~km}$ to summer at $90 \mathrm{~km}$. At the equator (Figures $3 c 1$ and $3 c 2$ ), the $C C$ between $N^{2}$ and $\left|T^{\prime}\right| / T_{0}$ are 0.33 and 0.65 at $80 \mathrm{~km}$ and $70 \mathrm{~km}$, respectively. However, the time series of $N^{2}$ and $\left|T^{\prime}\right| / T_{0}$ consist of more spectra and exhibit larger variability with time than those at $50^{\circ} \mathrm{N} / \mathrm{S}$. From Figure $3 \mathrm{~d}$, at low latitudes, al-

(a1) $50^{\circ} \mathrm{N}, 90 \mathrm{~km} \quad N^{2}(3.76,7.29)\left|T^{\prime}\right| / T_{0}(0.02,0.06)$

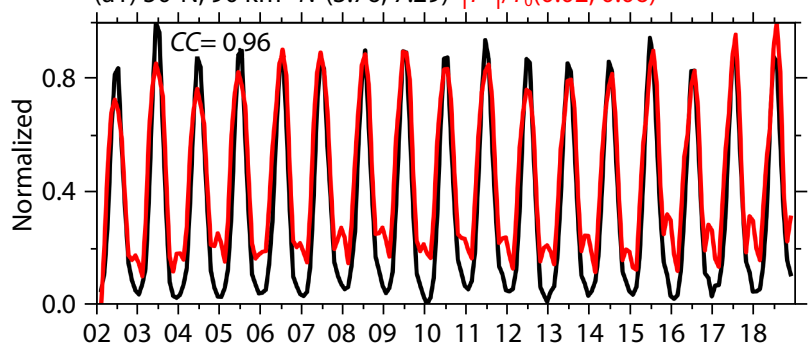

(b1) $50^{\circ} \mathrm{S}, 90 \mathrm{~km} \quad N^{2}(3.83,7.09)\left|T^{\prime}\right| / T_{0}(0.03,0.05)$

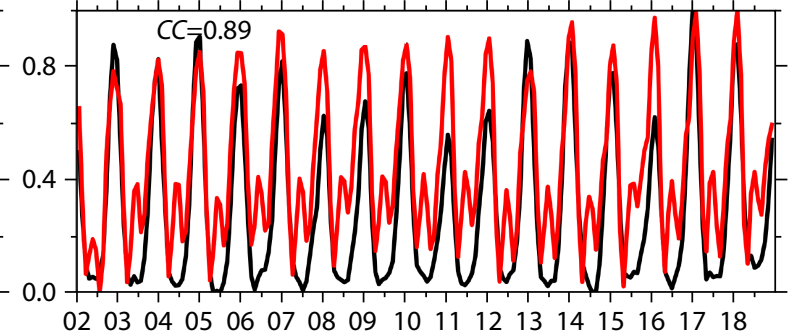

(a2) $50^{\circ} \mathrm{N}, 65 \mathrm{~km} \quad N^{2}(2.33,4.02)\left|T^{\prime}\right| / T_{0}(0.01,0.02)$

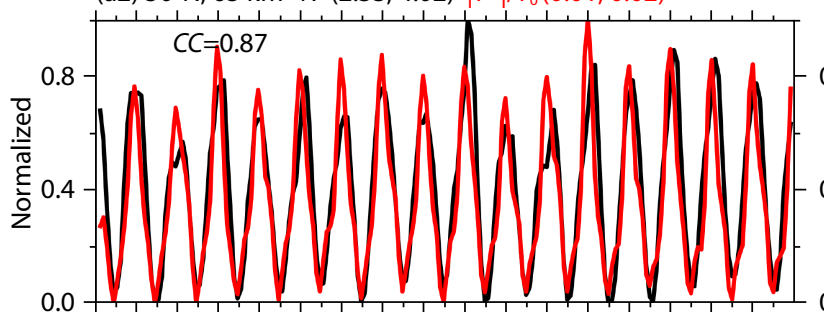

$\begin{array}{lllllllllllllllll}02 & 03 & 04 & 05 & 06 & 07 & 08 & 09 & 10 & 11 & 12 & 13 & 14 & 15 & 16 & 17 & 18 \\ \text { Year } & & & \end{array}$

(c1) Equ, $80 \mathrm{~km} N^{2}(4.08,7.38)\left|T^{\prime}\right| / T_{0}(0.02,0.03)$

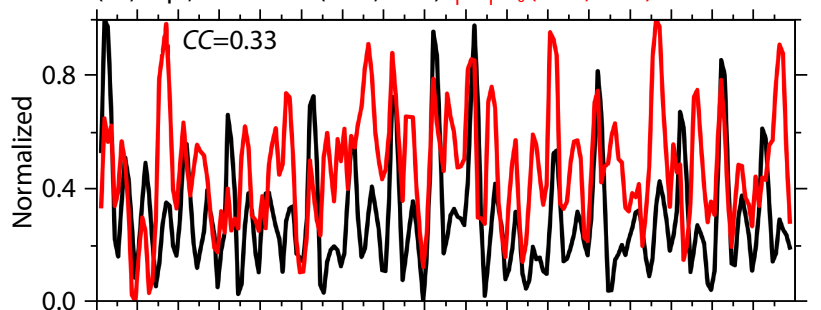

$\begin{array}{lllllllllllllllll}02 & 03 & 04 & 05 & 06 & 07 & 08 & 09 & 10 & 11 & 12 & 13 & 14 & 15 & 16 & 17 & 18\end{array}$ (c2) Equ, $70 \mathrm{~km} N^{2}(2.42,4.36)\left|T^{\prime}\right| / T_{0}(0.01,0.02)$

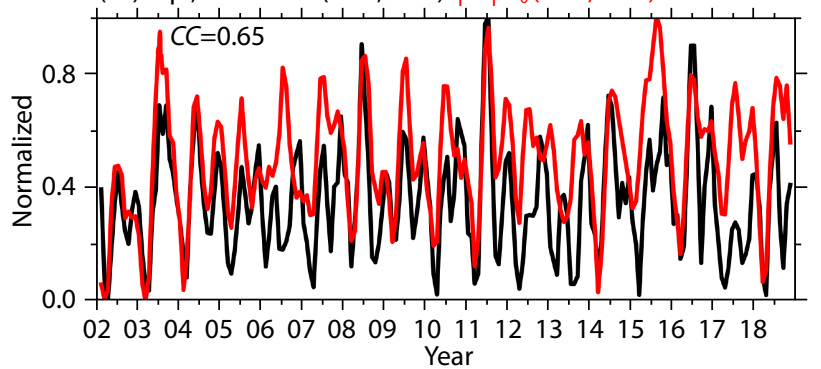

(b2) $50^{\circ} \mathrm{S}, 65 \mathrm{~km} \quad N^{2}(2.31,3.76)\left|T^{\prime}\right| / T_{0}(0.01,0.02)$
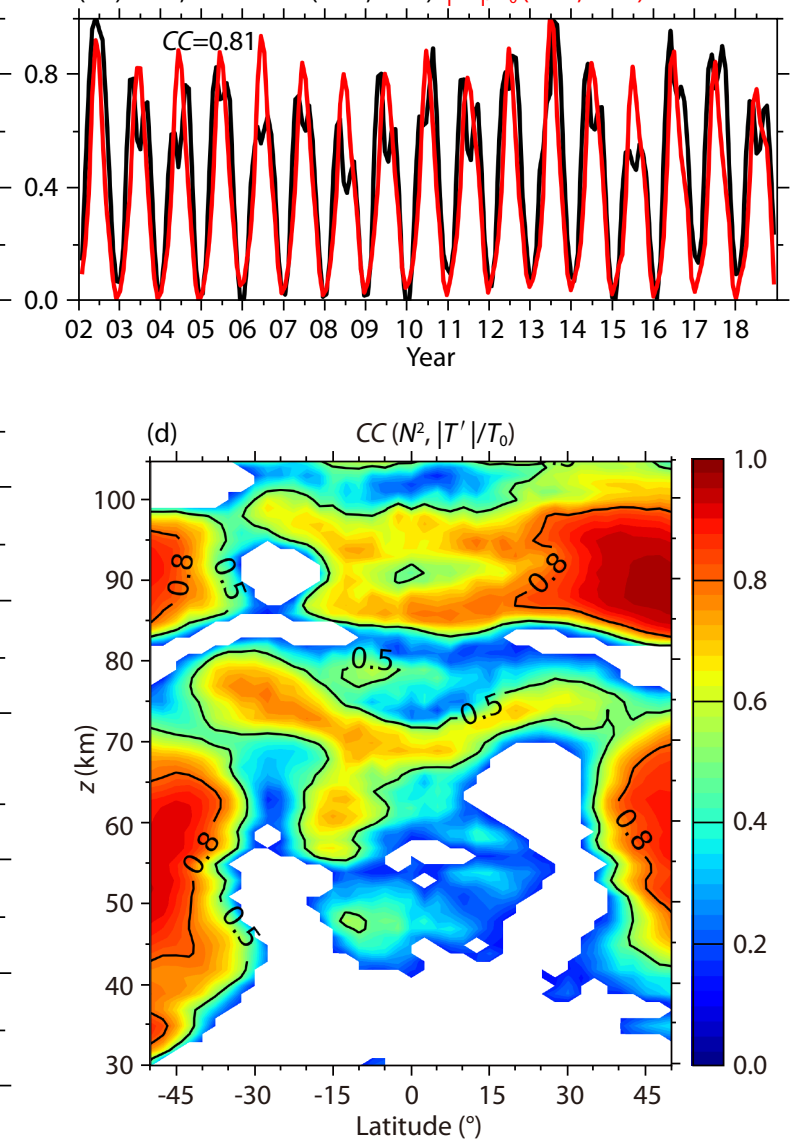

Figure 3. Time series of the normalized trimonthly running mean $N^{2}$ (black) and $\left|T^{\prime}\right| / T_{0}$ (red) at $90 \mathrm{~km}$ and $65 \mathrm{~km}$ of $50^{\circ} \mathrm{N}(\mathrm{a})$ and $50^{\circ} \mathrm{S}(\mathrm{b})$, and at $80 \mathrm{~km}$ and $70 \mathrm{~km}$ of the equator (c), and the latitude-height distributions of the correlation coefficients (CC, d) between $N^{2}$ and $\left|T^{\prime}\right| / T_{0}$. We normalized $N^{2}$ and $\left|T^{\prime}\right| / T_{0}$ from their [min, $\left.\max \right]$ to $[0,1]$ to make the figures more readable. The [min, $\left.\max \right]$ and $C C$ are noted in each panel. The white regions in (d) indicate CC below the threshold of the confidence level $\leq 95 \%$ or $C C \leq 0.1$. The contour lines in (d) indicate the CC of 0.5 and 0.8 . 
though there are regions with $C C \geq 0.5$ at $z \sim 65-70 \mathrm{~km}$ and $z$ 85-100 km, the relations between $N^{2}$ and $\left|T^{\prime}\right| / T_{0}$ are complex, as shown in Figures $3 c 1$ and $3 c 2$ and as discussed in the next paragraph. At high latitudes, the time series of $N^{2}$ and $\left|T^{\prime}\right| / T_{0}$ are nearly quasi-monochromatic and have $C C \geq 0.8$ in some regions. The regions having large $C C(\geq 0.8)$ are generally at latitudes poleward of $\sim 40^{\circ} \mathrm{N} / \mathrm{S}$ and are separated by a layer with $C C$ well below 0.5 at $z$ $\sim 70-85 \mathrm{~km}(z \sim 75-82 \mathrm{~km})$ over the high latitudes of the southern hemisphere (northern hemisphere). An exception is that the region having large $C C(\geq 0.8)$ extends to a wider range and from $20^{\circ} \mathrm{N}$ to $50^{\circ} \mathrm{N}$ at $z \sim 85-105 \mathrm{~km}$ compared with that in the southern hemisphere.

According to the linear GW theory presented at the beginning of this section, a possible explanation for the correlations between $N^{2}$ and $\left|T^{\prime}\right| / T_{0}$ is presented below. The propagation of GWs is influenced not only by the $N^{2}$ but also by the wind structure (Jones, 1969) and GW source. If the GW amplitudes are large enough to reach dynamic instability, then $N^{2}$ and $\left|T^{\prime}\right| / T_{0}$ should be positively correlated based on Equation (6). Otherwise, the GW amplitude is too small and is not prohibited solely by the $N^{2}$. Thus, any relations between $N^{2}$ and $\left|T^{\prime}\right| / T_{0}$ are possible. At lower latitudes, the main GW source is the tropical convection, which is quite spontaneous and intermittent (Fritts and Alexander, 2003). At low latitudes, the wind reversal varies frequently with time and height (Fig. 6 of Swinbank and Ortland, 2003; Fig. 4 of Smith et al., 2017). For example, Swinbank and Ortland (2003, Fig. 6) showed that the zonal wind exhibits SAO and changes from eastward to westward and then eastward at $z \sim 50-80 \mathrm{~km}(\sim 1.000-0.001 \mathrm{hPa})$ over the equator. These frequent wind reversals change or prohibit the upward propagation of GWs and contribute to the temporal and height variations of GWs together with $N^{2}$. Moreover, according to ray-tracing theory (Jones, 1969), the great variability in wind speed results in a large magnitude of $\partial \bar{u} / \partial z$ (where $\bar{u}$ is the background wind) and then variations in $k_{z}$. In summary, it is the spontaneousness and intermittency of GW sources and the highly variable wind environment in which GWs propagate that induce poor linear relations between $N^{2}$ and $\left|T^{\prime}\right| / T_{0}$ at low latitudes. At high latitudes, the wind direction is almost invariant with height for a half-year period (Fig. 5 of Swinbank and Ortland, 2003). The wind provides an environment in which GWs propagate; thus, it induces the variations in $k_{z}$. This will decrease the correlation between $N^{2}$ and $\left|T^{\prime}\right| / T_{0}$ to some extent, based on Equation (6). Thus, the temporal variations of GWs are influenced mainly by $N^{2}$ and less so by the background wind. This leads to good linear relations between $N^{2}$ and $\left|T^{\prime}\right| / T_{0}$ at high latitudes.

Figure $3 \mathrm{~d}$ shows that the $C C$ are well below 0.5 at $z \sim 70-85 \mathrm{~km}(z$ $\sim 80 \mathrm{~km}$ ) over the southern hemisphere (northern hemisphere) high latitudes. Below and above these regions, the $C C$ between $N^{2}$ and $\left|T^{\prime}\right| / T_{0}$ are large and can be used to explain the phase changes of AO in the GWs at high latitudes. Liu X et al. (2017, Fig. 3) showed the monthly zonal-mean relative GW potential energy, whose peak occurs below $z \sim 70 \mathrm{~km}$ in winter and above $z \sim 80 \mathrm{~km}$ in summer at $\sim 40-50^{\circ} \mathrm{N} / \mathrm{S}$. The feature that the GW peak changes with height has been revealed by observations from lidar, radar, and rocketsondes at the middle and high latitudes (Manson and Meek, 1988; Senft and Gardner, 1991; Wilson et al., 1991; Tsuda et al., 1994; Nakamura et al., 1996). We now propose that the GW peak changes with height are mainly caused by the corresponding variations of the background $N^{2}$ at high latitudes. According to the necessary condition for dynamical instability $(R i \leq 0.25)$, the enhanced $N^{2}$ can sustain GWs having large amplitudes in winter below $z \sim 70 \mathrm{~km}$ and in summer above $z \sim 80 \mathrm{~km}$. The enhanced $N^{2}$ in summer above $z \sim 80 \mathrm{~km}$ is due to the downward shift of the summer mesopause. The downward shift of the summer mesopause reduces the vertical extent of the mesosphere and thus increases the vertical gradient of the background temperature in summer. In turn, this reduces the $N^{2}$ in the summer mesosphere. On the contrary, the higher mesopause in winter increases the vertical extent of the mesosphere and reduces the vertical gradient of the background temperature. Thus, the peak of $N^{2}$ occurs below $z \sim 70 \mathrm{~km}$ in winter.

\section{Conclusions}

The $N^{2}$ is controlled by the background thermal structure, and it influences the generation, propagation, and dissipation of GWs. We calculated the $N^{2}$ and the amplitude of GWs by using temperature data derived from SABER measurements in the middle atmosphere over the past 17 years (2002-2018).

The altitude variations of $N^{2}$ depend on latitude and season. At low latitudes, a layer with enhanced $N^{2}$ occurs at $z \sim 20 \mathrm{~km}$, which is associated with the TIL and coincides with the results from satellite, radiosonde, and reanalysis data, as well as model simulations. The $N^{2}$ in this layer exhibits $A O$, with the peak shifting from below $z \sim 18 \mathrm{~km}$ in August to above $z \sim 18 \mathrm{~km}$ in March. Another layer with enhanced $N^{2}$ occurs in the upper mesosphere. This layer is associated with the MIL at low latitudes and a downward shift in the cold summer mesopause at high latitudes. The $N^{2}$ in this layer exhibits SAO at $z \sim 70-82 \mathrm{~km}$ at low latitudes, with phase shifting from $z \sim 70-75 \mathrm{~km}$ in June/December to $z \sim 75-82 \mathrm{~km}$ in April/October. Moreover, the $N^{2}$ in this layer exhibits prominent $\mathrm{AO}$ at high latitudes, with a phase shift from below $z \sim 70 \mathrm{~km}$ in winter to above $z \sim 85 \mathrm{~km}$ in summer in each hemisphere.

The correlations between $N^{2}$ and $\left|T^{\prime}\right| / T_{0}$ are large at latitudes poleward of $\sim 40^{\circ} \mathrm{N} / \mathrm{S}$ in general. A possible mechanism behind this is that the wind direction is almost invariant with height for a half-year period at high latitudes. Thus, the temporal variations of GWs are influenced mainly by $N^{2}$ and less by wind. The CC between $N^{2}$ and $\left|T^{\prime}\right| / T_{0}$ are large and can be partially used to explain the phase changes of AO in the GWs at high latitudes.

\section{Acknowledgments}

The SABER data were obtained from ftp://saber.gats-inc.com/Version2_0/Level2A/. This work was supported by the National Natural Science Foundation of China (grants 41831073 and 41874182). This work was also supported in part by the Specialized Research Fund and the Open Research Program of the State Key Laboratory of Space Weather.

\section{References}

Andrews, D. G., Holton, J. R., and Leovy, C. B. (1987). Middle Atmosphere Dynamics (pp. 489). Orlando, FL: Academic Press. 
Baldwin, M. P., Gray, L. J., Dunkerton, T. J., Hamilton, K., Haynes, P. H., Randel, W. J., Holton, J. R., Alexander, M. J., Hirota, I., ... Takahashi, M. (2001). The quasibiennial oscillation. Rev. Geophys., 39(2), 179-229. https://doi.org/10.1029/1999RG000073

Birner, T., Dörnbrack, A., and Schumann, U. (2002). How sharp is the tropopause at midlatitudes?. Geophys. Res. Lett., 29(14), 45-1. https://doi.org/10.1029/2002GL015142

Birner, T., Sankey, D., and Shepherd, T. G. (2006). The tropopause inversion layer in models and analyses. Geophys. Res. Lett., 33(14), L14804. https://doi.org/10.1029/2006GL026549

Eckermann, S. D., Hirota, I., and Hocking, W. K. (1995). Gravity wave and equatorial wave morphology of the stratosphere derived from long-term rocket soundings. Quart. J. Roy. Meteor. Soc., 121(521), 149-186. https://doi.org/10.1002/qj.49712152108

Fechine, J., Wrasse, C. M., Takahashi, H., Mlynczak, M. G., and Russell, J. M. (2008). Lower-mesospheric inversion layers over Brazilian equatorial region using TIMED/SABER temperature profiles. Adv. Space Res., 41(9), 1447-1453. https://doi.org/10.1016/j.asr.2007.04.070

Fritts, D. C., and Rastogi, P. K. (1985). Convective and dynamical instabilities due to gravity wave motions in the lower and middle atmosphere: Theory and observations. Radio Sci., 20(6), 1247-1277.

https://doi.org/10.1029/RS020i006p01247

Fritts, D. C., and Alexander, M. J. (2003). Gravity wave dynamics and effects in the middle atmosphere. Rev. Geophys., 41(1), 3-1. https://doi.org/10.1029/2001RG000106

Gan, Q., Zhang, S. D., and Yi, F. (2012). TIMED/SABER observations of lower mesospheric inversion layers at low and middle latitudes. J. Geophys. Res. Atmos, 117(7), D07109. https://doi.org/10.1029/2012JD017455

Gettelman, A., Hoor, P., Pan, L. L., Randel, W. J., Hegglin, M. I., and Birner, T. (2011). The extratropical upper troposphere and lower stratosphere. Rev. Geophys., 49(3), RG3003. https://doi.org/10.1029/2011RG000355

Grise, K. M., Thompson, D. W. J., and Birner, T. (2010). A global survey of static stability in the stratosphere and upper troposphere. J. Climate, 23(9), 2275-2292. https://doi.org/10.1175/2009JCLI3369.1

Gubenko, V. N., Pavelyev, A. G., and Andreev, V. E. (2008). Determination of the intrinsic frequency and other wave parameters from a single vertical temperature or density profile measurement. J. Geophys. Res.: Atmos., 113(D8), D08109. https://doi.org/10.1029/2007JD008920

Holton, J. R. (2004). An Introduction to Dynamic Meteorology: Fourth Edition (4th ed, pp. 535). San Diego, CA: Elsevier.

John, S. R., and Kumar, K. K. (2012). TIMED/SABER observations of global gravity wave climatology and their interannual variability from stratosphere to mesosphere lower thermosphere. Climate Dyn., 39(6), 1489-1505. https://doi.org/10.1007/s00382-012-1329-9

Jones, W. L. (1969). Ray tracing for internal gravity waves. J. Geophys. Res., 74(8), 2028-2033. https://doi.org/10.1029/JB074i008p02028

Krebsbach, M., and Preusse, P. (2007). Spectral analysis of gravity wave activity in SABER temperature data. Geophys. Res. Lett., 34(3), L03814. https://doi.org/10.1029/2006GL028040

Leblanc, T., and Hauchecorne, A. (1997). Recent observations of mesospheric temperature inversions. J. Geophys. Res.: Atmos., 102(D16), 19471-19482. https://doi.org/10.1029/97jd01445

Liu, H. L. (2007). On the large wind shear and fast meridional transport above the mesopause. Geophys. Res. Lett., 34(8), L08815.

https://doi.org/10.1029/2006GL028789

Liu, H. L. (2017). Large wind shears and their implications for diffusion in regions with enhanced static stability: The Mesopause and the Tropopause. J. Geophys. Res.: Atmos., 122(18), 9579-9590. https://doi.org/10.1002/2017JD026748

Liu, X., Xu, J. Y., Yue, J., Liu, H. L., and Yuan, W. (2014). Large winds and wind shears caused by the nonlinear interactions between gravity waves and tidal backgrounds in the mesosphere and lower thermosphere. J. Geophys. Res.: Space Phys., 119(9), 7698-7708. https://doi.org/10.1002/2014JA020221

Liu, X., Yue, J., Xu, J. Y., Garcia, R. R., Russell III, J. M., Mlynczak, M., Wu, D. L., and Nakamura, T. (2017). Variations of global gravity waves derived from 14 years of SABER temperature observations. J. Geophys. Res.: Atmos., 122(12),
6231-6249. https://doi.org/10.1002/2017JD026604

Liu, X., Xu, J. Y., Yue, J., Vadas, S. L., and Becker, E. (2019). Orographic primary and secondary gravity waves in the middle atmosphere from 16-year SABER observations. Geophys. Res. Lett., 46(8), 4512-4522. https://doi.org/10.1029/2019GL082256

Manson, A. H., and Meek, C. E. (1988). Gravity wave propagation characteristics (60-120 km) as determined by the Saskatoon MF radar (Gravnet) system: $1983-85$ at $52^{\circ} \mathrm{N}, 107^{\circ}$ W. J. Atmos. Sci., 45(6), 932-946. https://doi.org/10.1175/1520-0469(1988)045<0932:GWPCKA>2.0.CO;2

Meriwether, J. W., and Gerrard, A. J. (2004). Mesosphere inversion layers and stratosphere temperature enhancements. Rev. Geophys., 42(3), RG3003. https://doi.org/10.1029/2003RG000133

Nakamura, T., Tsuda, T., Fukao, S., Manson, A. H., Meek, C. E., Vincent, R. A., and Reid, I. M. (1996). Mesospheric gravity waves at Saskatoon $\left(52^{\circ} \mathrm{N}\right)$, Kyoto $\left(35^{\circ} \mathrm{N}\right)$, and Adelaide (35으). J. Geophys. Res.: Atmos., 101(D3), 7005-7012. https://doi.org/10.1029/95JD03826

Pilch Kedzierski, R., Neef, L., and Matthes, K. (2016). Tropopause sharpening by data assimilation. Geophys. Res. Lett., 43(15), 8298-8305. https://doi.org/10.1002/2016GL069936

Preusse, P., Eckermann, S. D., Ern, M., Oberheide, J., Picard, R. H., Roble, R. G., Riese, M., Russell, J. M., III, and Mlynczak, M. G. (2009). Global ray tracing simulations of the SABER gravity wave climatology. J. Geophys. Res.: Lett., 114(8), D08126. https://doi.org/10.1029/2008JD011214

Remsberg, E. E., Marshall, B. T., Garcia-Comas, M., Krueger, D., Lingenfelser, G. S., Martin-Torres, J., Mlynczak, G., Russell III, J. M., Smith, A. K., ... Thompson, R. E. (2008). Assessment of the quality of the version 1.07 temperature-versuspressure profiles of the middle atmosphere from TIMED/SABER. J. Geophys. Res.: Atmos., 113(D17), D17101. https://doi.org/10.1029/2008JD010013

Russell, J. M., III, Mlynczak, M. G., Gordley, L. L., Tansock, Jr., J. J., and Esplin, R. W. (1999). Overview of the SABER experiment and preliminary calibration results. In Proceedings Volume 3756, Optical Spectroscopic Techniques and Instrumentation for Atmospheric and Space Research III (pp. 277-288). Denver: SPIE. https://doi.org/10.1117/12.366382

Senft, D. C., and Gardner, C. S. (1991). Seasonal variability of gravity wave activity and spectra in the mesopause region at Urbana. J. Geophys. Res.: Atmos., 96(D9), 17229-17264. https://doi.org/10.1029/91jd01662

Shepherd, M. G., Evans, W. F. J., Hernandez, G., Offermann, D., and Takahashi, H. (2004). Global variability of mesospheric temperature: Mean temperature field. J. Geophys. Res.: Atmos., 109(D24), D24117. https://doi.org/10.1029/2004JD005054

Smith, A. K., Garcia, R. R., Moss, A. C., and Mitchell, N. J. (2017). The semiannual oscillation of the tropical zonal wind in the middle atmosphere derived from satellite geopotential height retrievals. J. Atmos. Sci., 74(8), 2413-2425. https://doi.org/10.1175/JAS-D-17-0067.1

Sunilkumar, S. V., Muhsin, M., Parameswaran, K., Venkat Ratnam, M., Ramkumar, G., Rajeev, K., Murthy, B. V. K., Namboodiri, K. V. S., Subrahmanyam, K. V., ... Shankar Das, S. (2015). Characteristics of turbulence in the troposphere and lower stratosphere over the Indian Peninsula. J. Atmos. Sol.-Terr. Phys., 133, 36-53. https://doi.org/10.1016/j.jastp.2015.07.015

Sunilkumar, S. V., Muhsin, M., Venkat Ratnam, M., Parameswaran, K., Krishna Murthy, B. V., and Emmanuel, M. (2017). Boundaries of tropical tropopause layer (TTL): A new perspective based on thermal and stability profiles. J. Geophys. Res.: Atmos., 122(2), 741-754. https://doi.org/10.1002/2016JD025217

Swinbank, R., and Ortland, D. A. (2003). Compilation of wind data for the Upper Atmosphere Research Satellite (UARS) reference atmosphere project. J. Geophys. Res.: Atmos., 108(D19), 4615. https://doi.org/10.1029/2002jd003135

Tsuda, T., Murayama, T., Nakamura, R., Vincent, R. A., Manson, A. H., Meek, C. E., and Wilson, R. L. (1994). Variations of the gravity wave characteristics with height, season and latitude revealed by comparative observations. J. Atmos. Terr. Phys., 56(5), 555-568. https://doi.org/10.1016/0021-9169(94)90097-3

Wilson, R., Chanin, M. L., and Hauchecorne, A. (1991). Gravity waves in the middle atmosphere observed by Rayleigh lidar: 2 Climatology. J. Geophys. Res.: Atmos., 96(D3), 5169-5183. https://doi.org/10.1029/90JD02610

Xu, J. Y., Liu, H. L., Yuan, W., Smith, A. K., Roble, R. G., Mertens, C. J., Russell II, J. 
M., and Mlynczak, M. G. (2007a). Mesopause structure from thermosphere, ionosphere, mesosphere, energetics, and dynamics (TIMED)/sounding of the atmosphere using broadband emission radiometry (SABER) observations. J. Geophys. Res.: Atmos., 112(D9), D09102. https://doi.org/10.1029/2006JD007711

Xu, J. Y., Smith, A. K., Yuan, W., Liu, H. L., Wu, Q., Mlynczak, M. G., and Russell III, J. M. (2007b). Global structure and long-term variations of zonal mean temperature observed by TIMED/SABER. J. Geophys. Res.: Atmos., 112(D24), D24106. https://doi.org/10.1029/2007JD008546

Xu, J. Y., Smith, A. K., Liu, H. L., Yuan, W., Wu, Q., Jiang, G. Y., Mlynczak, M. G., Russell III, J. M., and Franke, S. J. (2009). Seasonal and quasi-biennial variations in the migrating diurnal tide observed by Thermosphere, Ionosphere, Mesosphere, Energetics and Dynamics (TIMED). J. Geophys. Res.: Atmos., 114(D13), D13107. https://doi.org/10.1029/2008jd011298

Yamashita, C., England, S. L., Immel, T. J., and Chang, L. C. (2013). Gravity wave variations during elevated stratopause events using SABER observations. J. Geophys. Res.: Atmos., 118(11), 5287-5303.

https://doi.org/10.1002/jgrd.50474
Yue, J., She, C. Y., and Liu, H. L. (2010). Large wind shears and stabilities in the mesopause region observed by Na wind-temperature lidar at midlatitude. J. Geophys. Res.: Space Phys., 115(A10), A10307.

https://doi.org/10.1029/2009JA014864

Zhang, Y., Xiong, J., Liu, L., and Wan, W. (2012). A global morphology of gravity wave activity in the stratosphere revealed by the 8-year SABER/TIMED data. J. Geophys. Res.: Atmos., 117(D21), D21101. https://doi.org/10.1029/2012JD017676

Zhang, Y. H., Zhang, S. D., Huang, C. M., Huang, K. M., Gong, Y., and Gan, Q. (2015). The interaction between the tropopause inversion layer and the inertial gravity wave activities revealed by radiosonde observations at a midlatitude station. J. Geophys. Res.: Atmos., 120(16), 8099-8111. https://doi.org/10.1002/2015JD023115

Zhang, Y. H., Zhang, S. D., Huang, C. M., Huang, K. M., and Gong, Y. (2019). The tropopause inversion layer interaction with the inertial gravity wave activities and its latitudinal variability. J. Geophys. Res.: Atmos., 124(14), 7512-7522. https://doi.org/10.1029/2019JD030309 